\title{
Helicobacter pylori infection enhances heparanase leading to cell proliferation via mitogen-activated protein kinase signalling in human gastric cancer cells
}

\author{
LIPING LIU ${ }^{1-3 *}$, YONGXUN ZHAO ${ }^{4 *}$, GUANGRUI FAN $^{1}$, TIANKUI SHUAI ${ }^{3}, \mathrm{BIN} \mathrm{LI}^{2}$ and YUMIN LI \\ ${ }^{1}$ The Second Clinical Medical School of Lanzhou University, Lanzhou, Gansu 730030; \\ ${ }^{2}$ Department of Critical Care Medicine, The First Hospital of Lanzhou University, Lanzhou, Gansu 730000; \\ ${ }^{3}$ Department of Critical Care Medicine, The Donggang Branch of The First Hospital of Lanzhou University, \\ Lanzhou, Gansu 730030; ${ }^{4}$ Department of Surgical Oncology, The First Hospital of Lanzhou University, \\ Lanzhou, Gansu 730000; ${ }^{5}$ Department of General Surgery, The Second Hospital of Lanzhou University, \\ Key Laboratory of Digestive System Tumors of Gansu Province, Lanzhou, Gansu 730030, P.R. China
}

Received April 10, 2018; Accepted September 18, 2018

DOI: $10.3892 / \mathrm{mmr} .2018 .9558$

\begin{abstract}
Helicobacter pylori (H. pylori) infection is the most important factor in the development of gastric cancer. Heparanase (HPA) is involved in tissue remodelling and cell migration, which leads to inflammation and tumour metastasis. The current study aimed was to explore whether a $H$. pylori infection leads to an increase in the level of HPA in gastric cancer and to investigate the specific mechanism underlying this association. Reverse transcription-polymerase chain reaction and western blotting were used to detect HPA mRNA and protein expression, respectively, in MKN-45 cells infected by H. pylori, MKN-45 cells treated with the mitogen-activated protein kinase (MAPK) inhibitor SB203580 and MKN-45 cells transfected with small interfering RNA against HPA. MAPK and nuclear factor (NF) $\kappa \mathrm{B}$ expression were determined by western blotting in the different cells group. Cell Counting Kit-8, Transwell method, and Scratch and Clone tests were conducted to detect proliferation, invasion, migration and clone formation ability of gastric cancer cells. It was demonstrated that HPA mRNA expression was highest at $6 \mathrm{~h}$ post-infection, while the expression of the HPA protein was highest at $24 \mathrm{~h}$ post-infection in $H$. pylori-infected gastric cancer cells. Furthermore, it was demonstrated that $H$. pylori infection significantly enhanced the expression of MAPK and
\end{abstract}

Correspondence to: Professor Yumin Li, Department of General Surgery, The Second Hospital of Lanzhou University, Key Laboratory of Digestive System Tumors of Gansu Province, 82 Cuiying Gate, Chengguan, Lanzhou, Gansu 730030, P.R. China E-mail: liym@1zu.edu.cn

${ }^{*}$ Contributed equally

Key words: Helicobacter pylori, heparanase, mitogen-activated protein kinase, gastric cancer
$\mathrm{NF}-\kappa \mathrm{B}$ in MKN-45 cells at the mRNA and protein levels. SB203580 significantly decreased the expression of $N F-\kappa B$ in MKN-45 cells infected with H. pylori. Exposure to SB203580 also significantly decreased the expression of HPA. In the present study, the inhibition of HPA significantly lowered $H$. pylori-induced cell proliferation, suggesting that $H$. pylori infection induces the proliferation of gastric cancer cells through the upregulation of HPA. Taken together, the results of the present study demonstrated that HPA serves a critical role in the development of gastric cancer in $H$. pylori-infected cells, which may be an important mechanism through which H. pylori infection leads to gastric cancer. In addition, $H$. pylori infection promotes the proliferation, invasion and metastasis of gastric cancer cells through the upregulation of HPA expression, and this is likely mediated via the MAPK and $\mathrm{NF}-\kappa \mathrm{B}$ signalling pathways. These data suggest that HPA can be used as a therapeutic target in gastric cancer, particularly in cases induced by $H$. pylori infection.

\section{Introduction}

Gastric cancer is one of the most common and lethal malignancies, and is the third leading cause of cancer-associated mortality worldwide (1). The incidence of gastric cancer in China accounts for $>40 \%$ of newly diagnosed patients with gastric cancer in the world (2-4). At present, the pathogenesis of gastric cancer remains unclear; however, it is hypothesised that several factors, multiple steps and multiple genes serve important roles in gastric cancer pathogenesis $(5,6)$. The International Agency for Research on Cancer has classified Helicobacter pylori (H. pylori) as a class I carcinogen (7). $H$. pylori can exist in the acidic environment of the stomach for a long time and destroy the gastric mucosa, generating changes in the release of gastric mucosal hormones, thus affecting the physiological state of the stomach; therefore, it represents the most significant risk factor for malignant gastric tumours $(8,9)$. Approximately $50 \%$ of the world's population is infected with $H$. pylori $(10,11)$. The infection rate in China 
may be as high as $73.3 \%$ (12), particularly in the Beijing region, where the infection rate may reach up to $83.4 \%$ (13). Although an increasing number of studies have focussed on $H$. pylori infection resulting in gastric cancer, the underlying mechanism remains unknown.

Heparanase (HPA) is an endoglycosidase capable of degrading heparan sulfate in the extracellular matrix and basement membrane $(14,15)$, leading to the release numerous types of biological mediators, including fibroblast growth factor, hepatocyte growth factor and vascular endothelial growth factor, in response to local or systemic signals $(16,17)$. Thus, HPA is involved in tissue remodelling and cell migration, leading to inflammation, angiogenesis and tumour metastasis (18-21). Several studies have demonstrated that HPA is widely expressed in a number of tumours (22-24), including stomach, pancreas, colon and bladder tumours. In addition to its enzymatic activity, recent studies (25-27) revealed that the non-enzymatic activity of HPA promotes the aggregation of heparan sulfate proteoglycans, causing a cascade of intracellular signal amplification that results in the activation of protein kinase C, Src and Rac. HPA also acts on HPA receptors located on the cell surface, including mannose-6-phosphate receptor (MPR), cation-independent MPR and low density lipoprotein receptor-related protein, which causes signalling cascades. In addition, HPA serves an important role in inflammation and autoimmune diseases, including colitis, arthritis, psoriasis and sepsis $(28,29)$.

A number of studies have demonstrated that $H$. pylori infection leads to the development of gastric cancer by activating nuclear factor $(\mathrm{NF})-\kappa \mathrm{B}(30,31)$. Studies have also revealed that $\mathrm{NF}-\kappa \mathrm{B}$ upregulates the expression of HPA in numerous tumours (32-34). Furthermore, it has been demonstrated that $H$. pylori infection causes the development of gastric adenocarcinoma via the activation of mitogen-activated protein kinase (MAPK) $(35,36)$. MAPK is activated and translocated to the nucleus, leading to the activation of transcription factors, such as NF- $\mathrm{B}(37,38)$. Another study also demonstrated that the activation of the MAPK signalling pathway is closely associated with the expression of HPA (39). However, it is not clear whether MAPK is involved in the regulation of HPA expression following a $H$.pylori infection, leading to gastric cancer.

The present study aimed to investigate whether $H$. pylori infection causes the proliferation, invasion and metastasis of gastric cancer by affecting the expression and mechanisms of HPA. It was confirmed that $H$. pylori increased HPA expression via the MAPK and NF- $\mathrm{KB}$ signalling pathways in MKN-45 cells.

\section{Materials and methods}

Human cell and bacterial culture. Human gastric cancer MKN-45 cells were obtained from the Chinese Academy of Sciences (Shanghai, China) and cultivated in RPMI-1640 medium supplemented with $10 \%$ foetal bovine serum (FBS; both purchased from Hyclone; GE Healthcare Life Sciences, Logan, UT, USA), penicillin and streptomycin (both from North China Pharmaceutical Co., Inc., Shijiazhuang, China) in a humidified atmosphere containing $5 \% \mathrm{CO}_{2}$ at $37^{\circ} \mathrm{C}$.

H. pylori NCTC11637 bacteria were provided by the Key Laboratory of Digestive System Tumors of Gansu Province
(Lanzhou, China) and cultured on Columbia agar plates containing 7\% defibrinated goat blood (Solarbio Science and Technology Co., Ltd., Shanghai, China) in an anaerobic tank. Next, the bacteria were acquired and resuspended in RPMI-1640 medium without antibiotics, but containing $10 \%$ FBS. The optical density (OD) at $600 \mathrm{~nm}$ was used to measure the density of the bacteria (one unit of $\mathrm{OD}_{600}$ was equal to $1 \times 10^{8}$ colony-forming units $/ \mathrm{ml}$ ).

Co-culture of cells and bacteria. Following digestion, the MKN-45 cells were seeded into three culture dishes and cultured in physiological conditions until they reached the logarithmic growth phase. Next, the old medium was discarded and replaced with RPMI 1640 medium without antibiotics supplemented with FBS. $H$. pylori were then added to the MKN-45 cells in a bacterium to cell ratio of 100:1. The bacteria and cells were co-cultured for $6 \mathrm{~h}$ at $37^{\circ} \mathrm{C}$ in an atmosphere with $5 \% \mathrm{CO}_{2}$ and saturated humidity, at which point HPA expression was measured by reverse transcription-quantitative polymerase chain reaction (RT-qPCR) and western blotting.

Transfection and reagents. A small interfering RNA (siRNA) against HPA and scrambled siRNA were purchased from Santa Cruz Biotechnology, Inc. (Dallas, TX, USA). The siRNA sense strand for HPA was 5'-AGUCCGUCCAUUCAAAUAGUA GUGA-3', and the antisense strand was 5'-UCACUACUAUUU GAAUGGACGGACU-3'. The scrambled siRNA sense strand was 5'-UCUAAGCGAGAAUUCGUACGAUAUC-3', and the antisense strand was 5'-ACGUGACACGUUCGGAUAAUU AUCU-3'. Lipofectamine ${ }^{\mathrm{TM}} 2000$ (Santa Cruz Biotechnology, Inc.) was used to transfect the siRNA sequences, according to the manufacturer's protocol. SB203580, a p38 MAPK inhibitor, was purchased from Selleck Chemicals (Houston, TX, USA). SB203580 (20 $\mu \mathrm{M})$ was added to MKN-45 cells for $2 \mathrm{~h}$ prior to the co-culture with $H$. pylori to confirm that the MAPK signalling pathway was involved in $H$. pylori-induced HPA expression in gastric cancer cells. Cells were then used in RT-qPCR, western blotting, Cell Counting kit-8 (CCK-8), the Transwell method and the Scratch test.

$R T$-qPCR assay. Total RNA was extracted from the cells using TRIzol reagent (Takara Biotechnology Co., Ltd., Dalian, China) supplemented with trichloromethane, isopropanol and ethyl alcohol (all obtained from Lianchuang Biotechnology Co., Ltd., Lanzhou, China). RNA quality was analysed using spectrophotometry (Nanodrop 2000). Next, total RNA was reverse transcribed into cDNA using the PrimeScript ${ }^{\mathrm{TM}}$ RT Reagent kit (Takara Biotechnology Co., Ltd.) in accordance with the manufacturer's protocols. The RT reaction was performed for $5 \mathrm{sec}$ at $85^{\circ} \mathrm{C}$ and $15 \mathrm{~min}$ at $37^{\circ} \mathrm{C}$. The primers used in qPCR were designed by the Key Laboratory of Digestive System Tumors of Gansu Province and synthesised by Lianchuang Biotechnology Co., Ltd. (GenBank accession no. NM002046). The primer sequences were as follows: HPA sense, 5'-CCTCAT CCTCCTGGGTTCTC-3' and antisense, 5'-TATCCTGGTTGA CTTGAGATTGC-3'; and GAPDH sense, 5'-AAGGCTGGG GCTCATTTG-3' and antisense, 5'-AGGAGGCATTGCTGA TGATC-3'. The qPCR amplifications were performed using 7500/7500 Fast Real-Time PCR system (Applied Biosystems; Thermo Fisher Scientific, Inc., Waltham, MA, USA) and 
SYBR $^{\circledR}$ Premix Ex Taq ${ }^{\mathrm{TM}}$ II (Takara Biotechnology Co., Ltd.). According to the manufacturer's protocol, a $20 \mu \mathrm{l}$ reaction volume was used, and the thermal cycling conditions were as follows: $95^{\circ} \mathrm{C}$ for $30 \mathrm{sec}$, followed by 40 cycles of $95^{\circ} \mathrm{C}$ for $5 \mathrm{sec}$ and $60^{\circ} \mathrm{C}$ for $34 \mathrm{sec}$. HPA mRNA levels were quantified using ABI Prism $7900 \mathrm{HT}$ and the $2^{-\Delta \Delta \mathrm{Cq}}$ method (40) was used to analyze the results.

Western blot analysis. The treated cells were washed with ice-cold PBS, and total protein was extracted from the cells using radioimmunoprecipitation assay lysis buffer, phenylmethane sulfonyl fluoride (both from Beyotime Institute of Biotechnology, Haimen, China) and protein phosphatase inhibitor (Solarbio Science and Technology Co., Ltd.). The protein concentration was measured using a BCA protein assay (Beyotime Institute of Biotechnology) subsequent to centrifugation at $13,000 \mathrm{x} \mathrm{g}$ for $30 \mathrm{~min}$ at $4^{\circ} \mathrm{C}$. Next, the protein was separated on a $10 \%$ gel by SDS-PAGE and then transferred onto polyvinylidene fluoride membranes (Solarbio Science and Technology Co., Ltd.), which were subsequently blocked with $5 \%$ non-fat milk for $2 \mathrm{~h}$ at $4^{\circ} \mathrm{C}$. Following the blocking step, the membranes were incubated with the following primary antibodies: anti-HPA1 $(1: 1,000$; cat. no. ab128931), anti-phosphorylated (p)-p38 MAPK (1:1,000; cat. no. ab195049), anti-p38 MAPK (1:1,000; cat. no. ab170099),

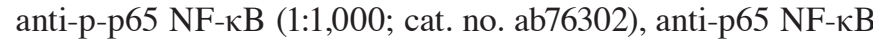
(1:1,000; no. ab32536; all Abcam, Cambridge, UK) and anti- $\beta$-actin (1:2,000; cat. no. TA-09; OriGene Technologies, Inc., Beijing, China). Following overnight incubation at $4^{\circ} \mathrm{C}$, the membranes were washed three times with Tris-buffered saline/Tween-20 (Solarbio Science and Technology Co., Ltd.) and then incubated with horseradish peroxidase-conjugated secondary antibodies (1:10,000; cat. no. ZA-2301; OriGene Technologies, Inc.) at room temperature for $1 \mathrm{~h}$. The SuperSignal West Pico Chemiluminescent Substrate (Thermo Fisher Scientific, Inc.) was used to visualise the protein bands, which were imaged using the VersaDoc Imaging System (Bio-Rad Laboratories, Inc., Hercules, CA, USA). Densitometry measurements were performed to analyze protein expression using Bio-Rad Quantity One Software, version 4.62 (Bio-Rad Laboratories, Inc.).

CCK-8 assay. CCK-8 assay is designed to detect cell proliferation. Briefly, cells were seeded in 96-well plates at a density of $1 \times 10^{4}$ cells per well. SB203580 (20 $\left.\mu \mathrm{M}\right)$ was added to MKN-45 cells for $2 \mathrm{~h}$ prior to the co-culture with H. pylori, and then $100 \mu \mathrm{l}$ complete medium and $10 \mu \mathrm{l}$ CCK-8 reagent was added to each well. After the cells were incubated at $37^{\circ} \mathrm{C}$ in an atmosphere with $5 \% \mathrm{CO}_{2}$ and saturated humidity for $4 \mathrm{~h}$, the absorbance was detected at a wavelength of $450 \mathrm{~nm}$ using a multifunctional enzyme marking instrument.

Colony formation assay. The different groups of cells were cultured for $72 \mathrm{~h}$. Next, cells were seeded into 6-well culture plates at a density of 300 cells per well, and cell culture medium was added to the wells. Following a 14-day incubation, the cells were washed twice with PBS, fixed at room temperature for 15 min using $99 \%$ methanol and stained with crystal violet solution for $20 \mathrm{~min}$. Images were captured and the number of clones were counted using a microscope.
Transwell assay. A Transwell assay was used to detect the invasion capability of the tumour cells. Briefly, a 1:8 mixture of Matrigel gel to RPMI-1640 medium $(100 \mu \mathrm{l})$ was added to the lower chamber, which was placed in 24 -well plates at $37^{\circ} \mathrm{C}$ for $24 \mathrm{~h}$. A serum-free cell suspension $(200 \mu \mathrm{l})$ at a concentration of $2.5 \times 10^{5}$ cells $/ \mathrm{ml}$ was added to the upper chamber, while serum-containing medium was added to the lower chamber. Subsequently, the cells were cultured at $37^{\circ} \mathrm{C}$ in an atmosphere with $5 \% \mathrm{CO}_{2}$ and saturated humidity for $24 \mathrm{~h}$. Following incubation, the cells remaining in the upper chamber were carefully wiped off, and cells in the lower chamber was rinsed twice with PBS and fixed in methanol for $15 \mathrm{~min}$. The cells were stained with crystal violet solution in methanol for $30 \mathrm{~min}$, and then the excess crystal violet was washed off. Finally, the cells were observed and images were obtained using a microscope. The number of invading cells was counted in several fields of view.

Scratch test. The scratch test was used to detect the migration ability of tumour cells. Briefly, horizontal lines were drawn every $0.5-1 \mathrm{~cm}$ on the back of a 6 -well plate, and $5 \times 10^{5}$ cells were added to each well. The cells were incubated overnight until $100 \%$ confluence was reached, and then a scratch was made across the dish with a $200 \mathrm{ml}$ pipette. Subsequently, the cells were rinsed twice with $\mathrm{PBS}$, serum-free medium was added, and the cells were incubated at $37^{\circ} \mathrm{C}$ in an atmosphere with $5 \% \mathrm{CO}_{2}$. Following the incubation, images of the cells were obtained, and the migration distance was measured.

Statistical analysis. IBM SPSS software (version 22.0; IBM Corp., Armonk, NY, USA) was used to analyse all data. The experimental data are expressed as the mean \pm standard deviation. SigmaPlot (version 13.0; Systat Software, Inc., Chicago, IL, USA) was used to construct the graphs. $\mathrm{P}<0.05$ indicated that the difference between groups was statistically significant.

\section{Results}

H. pylori infection induces changes in HPA expression in MKN-45 cells in a time-dependent manner. According to previously published studies, the ratio of bacteria to gastric cancer cells is $\sim 100: 1(41,42)$; therefore, this ratio was used in the experiments conducted in the current study. To detect the effects of $H$. pylori infection on HPA expression in gastric cancer cells, $H$. pylori and MKN-45 cells were co-cultured at the aforementioned ratio for $0,6,12,24$ and $48 \mathrm{~h}$. The mRNA expression levels of HPA in MKN-45 cells were analysed by RT-qPCR assays. The co-culture of $H$. pylori and MKN-45 cells induced a significant increase in the mRNA expression level of HPA, which reached a peak level at $6 \mathrm{~h}$ and then decreased (Fig. 1A). The findings of western blot analysis supported the RT-qPCR results, demonstrating that HPA expression was also enhanced at the protein level (Fig. 1B and C). The HPA protein level peaked at $24 \mathrm{~h}$ in H. pylori-infected gastric cancer cells. Taken together, these results indicated that gastric cancer cells infected with H. pylori had increased HPA, in a time-dependent manner.

H. pylori infection mediates the increase of HPA expression in $M K N-45$ cells via the MAPK signalling pathway. To illustrate 
whether MAPK signalling is involved in the $H$.pylori-induced expression of HPA, the expression of p-p38 MAPK was detected by western blot analysis after $H$. pylori and MKN-45 cells were co-cultured for $0,30,60,120$ and $480 \mathrm{~min}$. The expression of p-p38 MAPK was significantly higher at $30 \mathrm{~min}$ and peaked at $60 \mathrm{~min}$, whereas the expression of p38 MAPK remained unchanged (Fig. 2A and B). To further confirm that $H$. pylori induces the activation of the MAPK signalling pathway, leading to the activation of NF- $\kappa B$ of MKN-45 cells, the expression of p-p65 NF- $\mathrm{kB}$ was also detected by western blot analysis following co-culture of $H$. pylori and MKN-45 cells for 0-480 min. The expression of p-p65 NF- $\mathrm{kB}$ gradually increased with the duration of the co-culture, peaking at 240 min (Fig. 2A and C). Furthermore, MKN-45 cells were pre-treated with a MAPK inhibitor, SB203580, for $2 \mathrm{~h}$ prior to co-culture with $H$. pylori. The expression of $\mathrm{p} 65 \mathrm{NF}-\kappa \mathrm{B}$ was significantly lower when MKN-45 cells co-cultured with H. pylori were pre-treated with SB203580 (Fig. 2D and E). Therefore, the results revealed that the MAPK/NF- $\mathrm{KB}$ signalling pathway may participate in $H$. pylori-induced HPA expression in gastric cancer cells, which requires further investigation.

Inhibition of MAPK weakens HPA expression when H. pylori and MKN-45 cells are co-cultured. To further illustrate whether the $H$. pylori-induced upregulation of HPA was mediated through the MAPK signalling pathway, $20 \mu \mathrm{M}$ SB203580 was added to MKN-45 cells for $2 \mathrm{~h}$ prior to the co-culture with $H$. pylori. The HPA mRNA expression was significantly higher when $H$. pylori infected the MKN-45 cells, but that upregulation was significantly prevented by SB203580 (Fig. 3A). These changes were also reflected at the protein level (Fig. 3B and C). Furthermore, the CCK-8 proliferation assay confirmed that the addition of SB203580 to H.pylori-infected MKN-45 cells significantly reduced the cell proliferation, as compared with that in untreated $H$. pylori-infected MKN-45 cells (Fig. 3D). In addition, the Transwell invasion (Fig. 3E and $\mathrm{F}$ ) and scratch test migration (Fig. 3G and $\mathrm{H}$ ) assays confirmed that the addition of SB203580 to H.pylori-infected MKN-45 cells markedly decreased the invasion and migration abilities of MKN- 45 cells, respectively. These results indicated that the MAPK signalling pathway was involved in the $H$. pylori-induced upregulation of HPA in gastric cancer cells.

HPA inhibition attenuated the H. pylori-induced proliferation of $M K N-45$ cells. When MKN-45 cells were transfected with siRNA against HPA, the HPA mRNA and protein expression levels were significantly decreased ( 88 and $83 \%$, respectively; Fig. 4A-C). To verify the involvement of HPA in the proliferation of gastric cancer cells induced by a $H$. pylori infection, the expression of HPA in $H$. pylori-infected HPA-knockout MKN-45 cells was detected by RT-qPCR analysis and western blotting. The results indicated that the expression level of HPA in $H$. pylori-infected HPA-knockout MKN-45 cells was significantly lower compared with that in $H$. pylori-infected MKN-45 cells at the mRNA and protein levels (Fig. 4D-F). Furthermore, it was revealed that proliferation (Fig. 4G) and colony formation (Fig. 4H and I) were significantly attenuated by HPA knockout in $H$. pylori-infected MKN-45 cells. These results revealed that HPA may have the potential to become
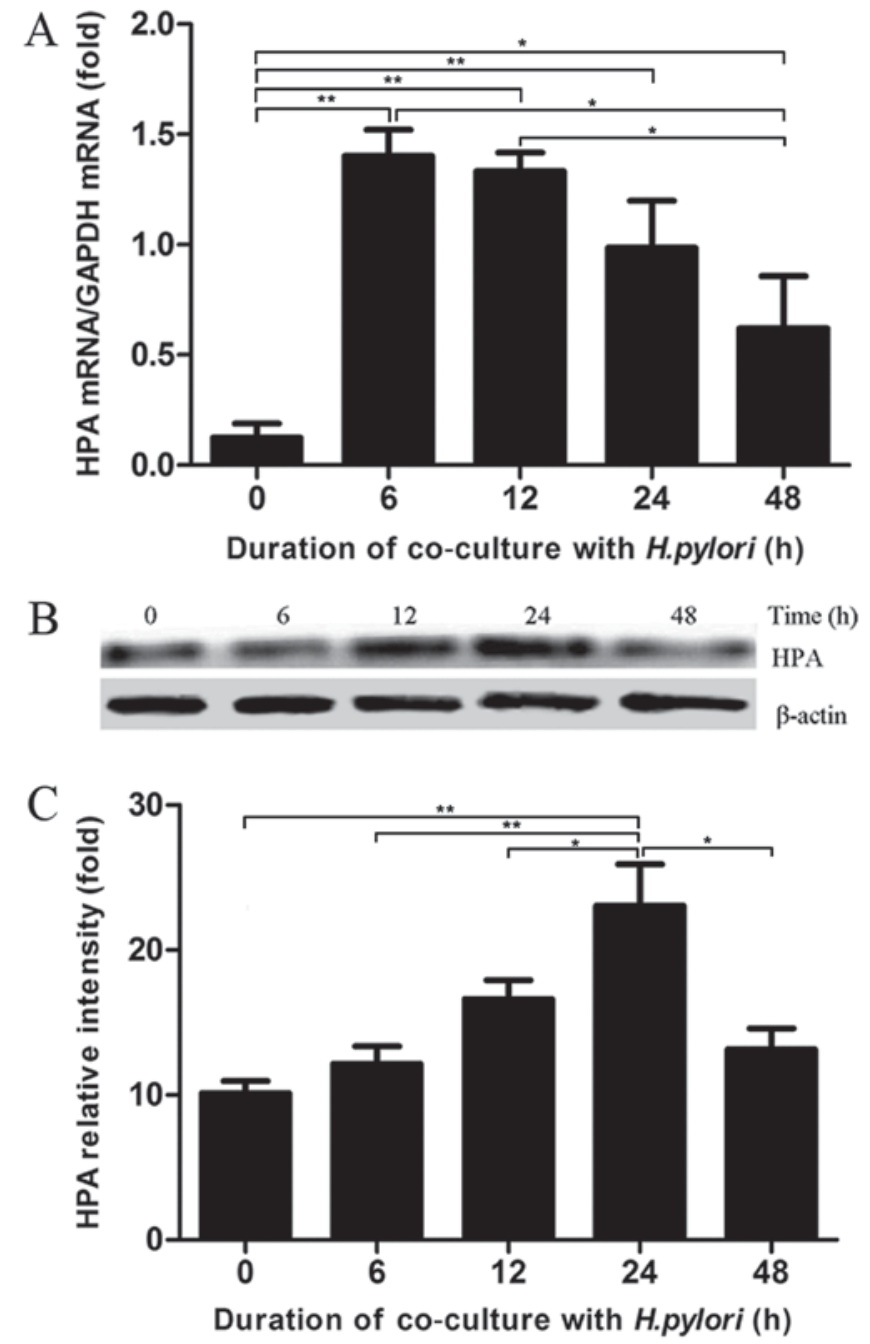

Figure 1. H. pylori infection enhances HPA expression in MKN-45 cells in a time-dependent manner. H. pylori and MKN-45 cells were co-cultured for $0,6,12,24$ and 48 h. (A) HPA mRNA expression was detected by reverse transcription-quantitative polymerase chain reaction. (B) Western blots and (C) quantitative results of HPA protein expression are shown. HPA mRNA expression was the highest at $6 \mathrm{~h}$ and then gradually decreased, while HPA protein expression was the highest at $24 \mathrm{~h}$ and then decreased. ${ }^{*} \mathrm{P}<0.05$ and ${ }^{* *} \mathrm{P}<0.01$, as indicated. H. pylori, Helicobacter pylori; HPA, heparanase.

a target for the treatment of gastric cancer, especially when H. pylori infection occurs.

\section{Discussion}

The present study demonstrated that $H$. pylori infection resulted in increased HPA expression in gastric cancer cells via the MAPK signalling pathway, thus exacerbating the degree of the proliferation and invasion of gastric cancer cells.

H. pylori infections cause several digestive diseases, including gastritis, gastric ulcers, gastric cancer, liver cancer and other diseases $(43,44)$. H. pylori infection is the most prominent risk factor for gastric cancer, which is one of the most common type of malignancy worldwide (45). However, the exact mechanism by which $H$. pylori infection causes gastric cancer has been unclear. HPA has been documented in numerous primary human tumours (46-48), such as gastric 

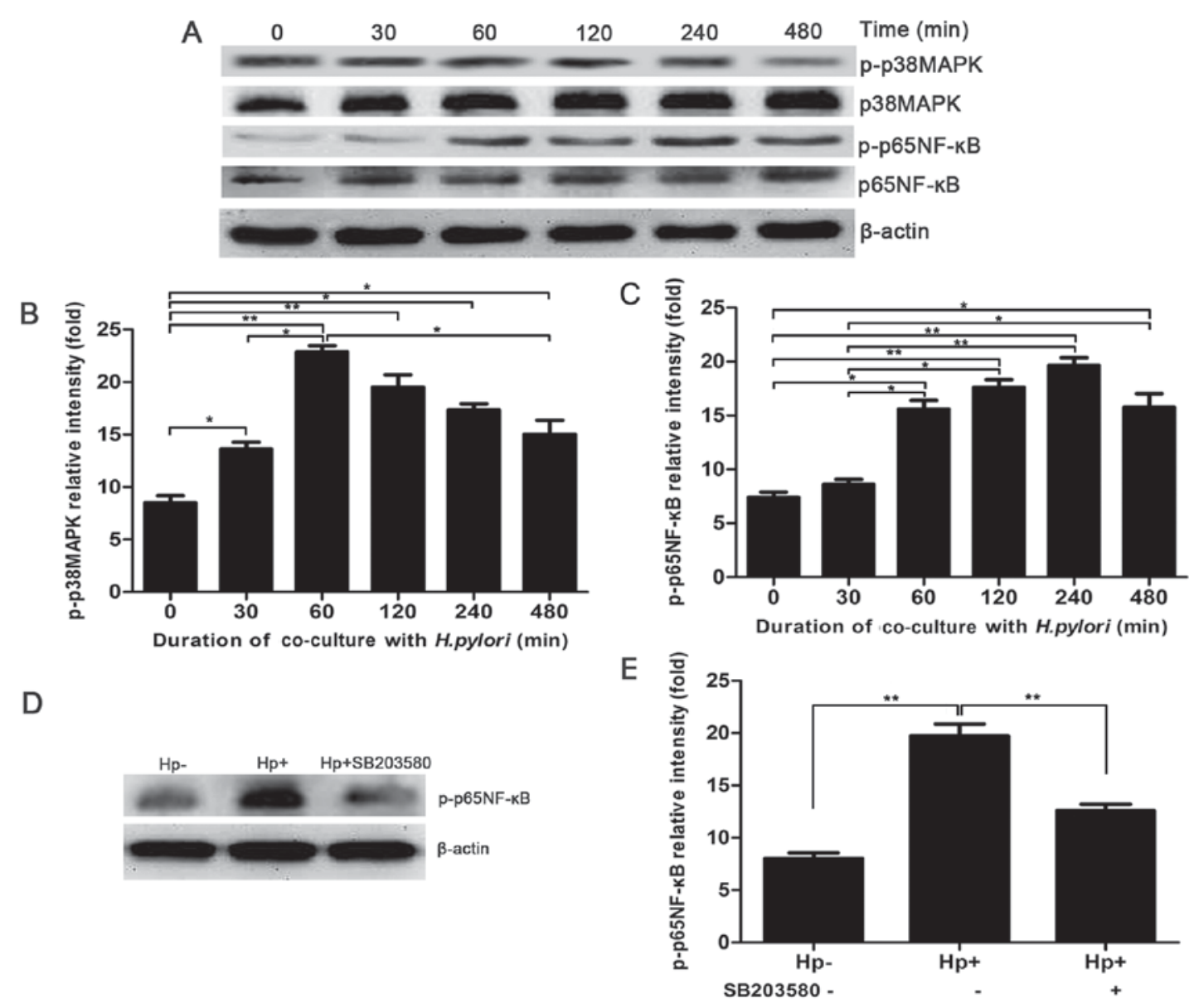

Figure 2. H. pylori infection mediates the HPA protein expression increase in MKN-45 cells via the MAPK signalling pathway. (A) Western blotting was used to detect the expression levels of p-p38 MAPK, p38 MAPK, p-p65 NF- $\mathrm{B}$ and p65 NF-kB following different co-culture durations. (B) p-p38 MAPK protein expression. (C) p-p65 NF- $\mathrm{BB}$ protein expression levels were quantitatively analysed using densitometry. (D) Western blots and (E) quantitatively analysed expression of NF- $\mathrm{KB}$ in MKN-45 cells pre-treated with SB203580 prior to co-culture with H. pylori. " $\mathrm{P}<0.05$ and ${ }^{* *} \mathrm{P}<0.01$, as indicated. MAPK,

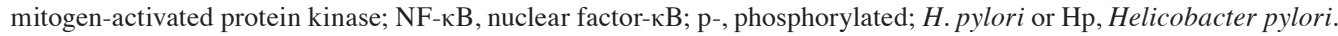

cancer (49), and previous studies have demonstrated that $H$.pylori infection is vital in the acceleration of tumour growth, angiogenesis and tumour metastasis (50-52). The current study also confirmed that HPA was highly expressed in gastric cancer cells, as previously reported in the literature $(53,54)$, and that the expression of HPA was greater in $H$. pylori-infected gastric cancer cells. Additionally, the present study demonstrated that the mRNA expression level of HPA was highest at $6 \mathrm{~h}$, while the protein expression level of HPA was highest at $24 \mathrm{~h}$ in $\mathrm{H}$. pylori-infected gastric cancer cells. These findings demonstrated that HPA expression is higher in gastric cancer, and that peak transcription and translation in tumours occur at 6 and $24 \mathrm{~h}$ post-infection, respectively.

Studies have indicated that $H$. pylori infection activates MAPK signalling in gastric epithelial cells (35) and gastric adenocarcinoma (36). The MAPK signalling pathway is composed of three major components, including extracellular signal-regulated kinase, c-Jun N-terminal kinase and p38 MAPK, and serves an important role in mediating a number of cellular events, such as genetic transcription, cell adhesion, cell metabolism and apoptosis $(55,56)$. The physiological function of MAPK is to produce different reactions to extracellular stimuli, and its main targets are transcription factors, such as NF- $\kappa B(57)$. When a cell is exposed to external stimuli, MAPK is phosphorylated, activated and translocated to the nucleus, where it activates NF- $\kappa \mathrm{B}$, initiating gene expression and completing the cellular reaction induced by its activation (58). Multiple studies have demonstrated that $H$. pylori infection induces gastric cancer by activating NF- $\mathrm{KB}(30,31)$. It has also been reported that NF- $\kappa \mathrm{B}$ can increase the expression of HPA in multiple tumours $(32,34,59,60)$. Specifically, studies have revealed that NF- $\mathrm{KB}$ was closely associated with the expression of HPA in gastric cancer cells and tissues $(61,62)$. Another previous study reported that the activation of the MAPK signalling pathway increased HPA expression in cancer (39). The current study further proved that $H$. pylori infection significantly enhanced the expression levels of MAPK and NF- $\kappa B$ in MKN-45 cells at the mRNA and protein levels. MAPK expression peaked at $60 \mathrm{~min}$ and NF- $\mathrm{\kappa B}$ expression peaked at $240 \mathrm{~min}$. Additionally, the inhibition of MAPK by SB203580 significantly decreased the expression of NF- $\mathrm{KB}$, indicating that MAPK was activated by $H$. pylori and then activated NF- $\mathrm{KB}$ in the cell nucleus. Based on the aforementioned results indicating that HPA transcription and translation in $H$. pylori-infected MKN-45 cells peaked at 6 and $24 \mathrm{~h}$, respectively, the authors of the current study speculate that H. pylori infection in gastric cancer activates MAPK/NF- $\kappa \mathrm{B}$ signalling, thus leading to the activation of HPA. 

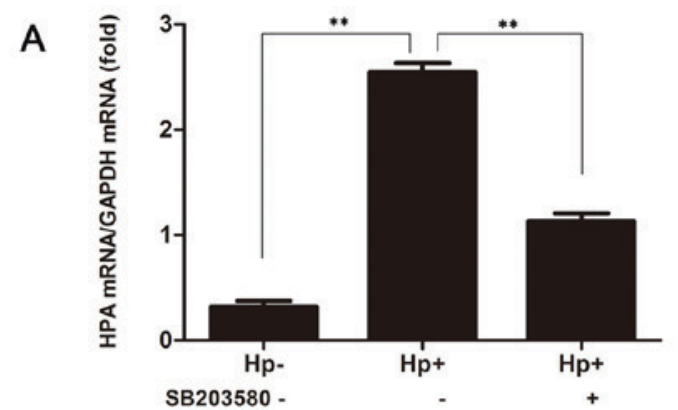

C

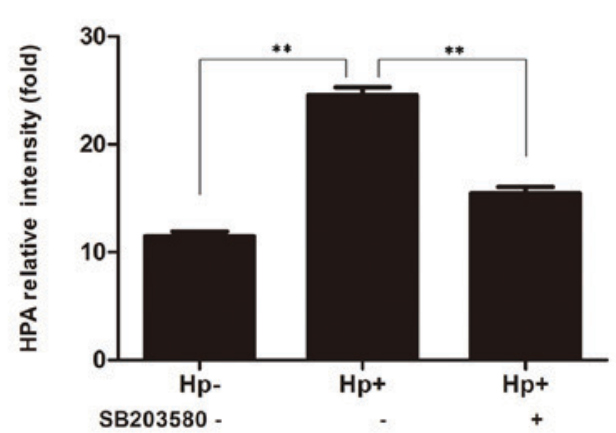

$\mathrm{E}$

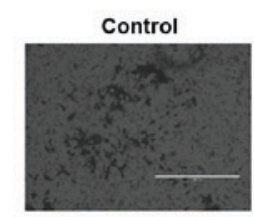

$\mathrm{Hp}+\mathrm{SB} 203580$

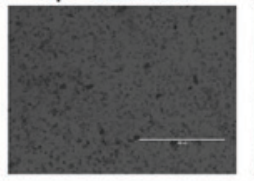

$\mathrm{Oh}$
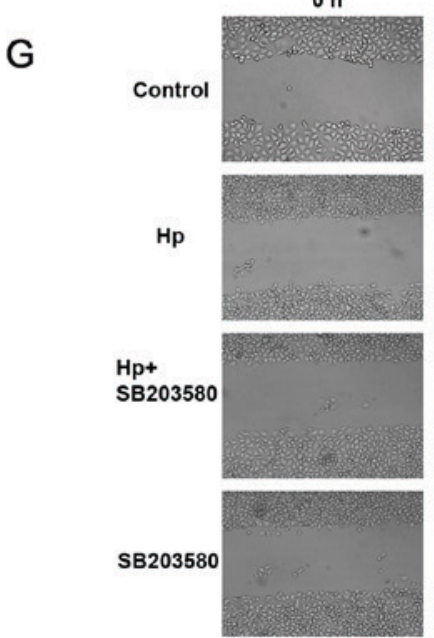

$\mathrm{Hp}$

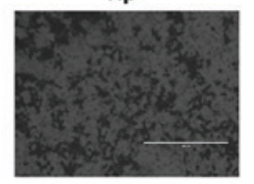

SB203580

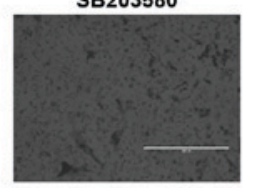

$24 \mathrm{~h}$
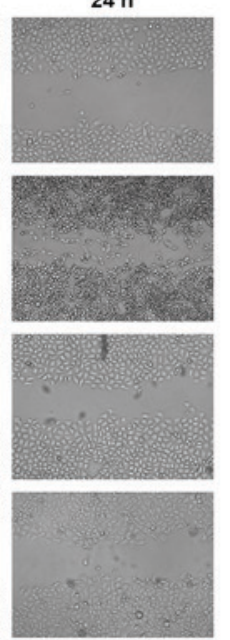

B

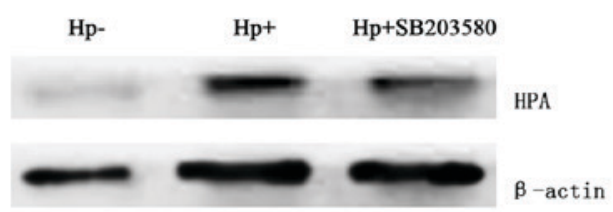

D

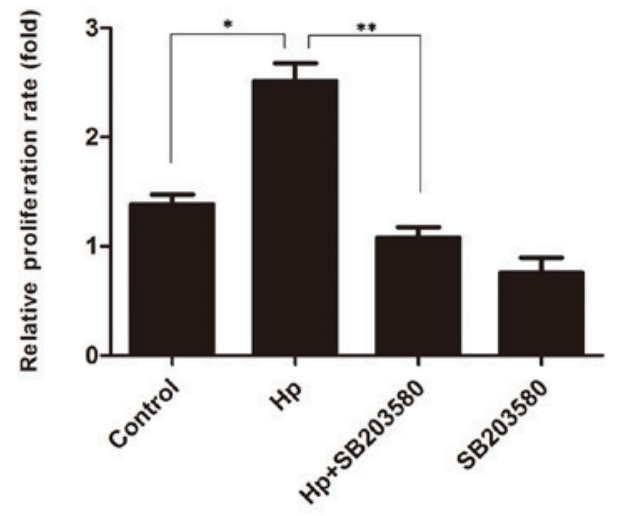

$\mathrm{F}$

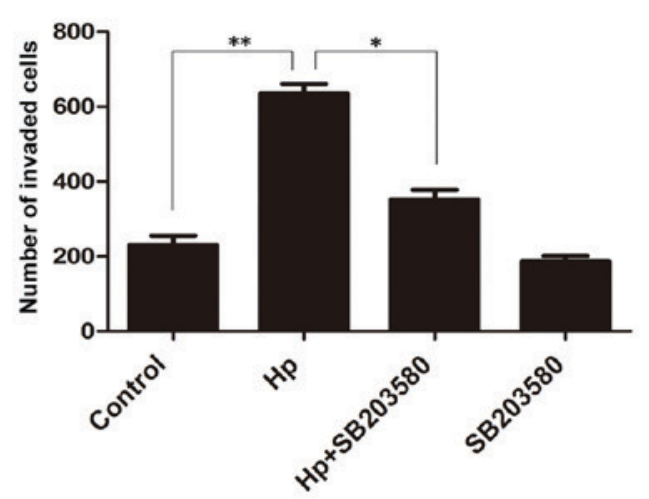

$\mathrm{H}$

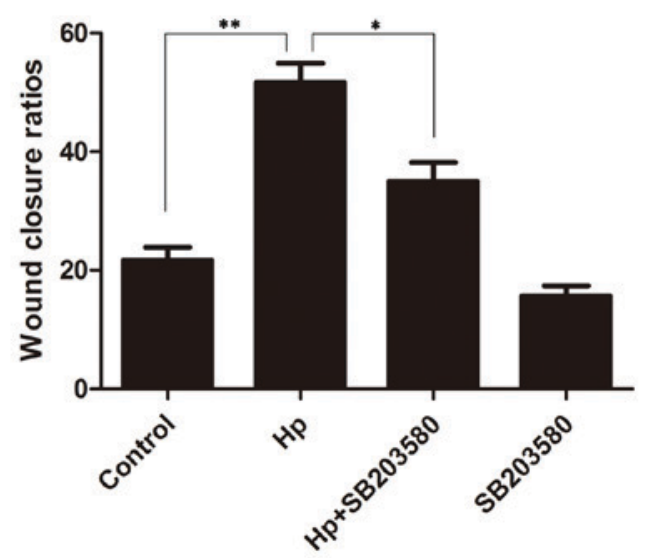

Figure 3. H. pylori infection enhances HPA expression in MKN-45 cells via the mitogen-activated protein kinase signalling pathway. Data were analysed in the untreated control cells, MKN-45 cells co-cultured with $H$. pylori, and MKN-45 cells pre-treated with SB203580 prior to co-culture with $H$. pylori. (A) Expression of the HPA mRNA. (B) Western blots and (C) quantified levels of HPA protein in the three groups. (D) Cell proliferation rate in the three groups was assessed using a Cell Counting Kit- 8 proliferation assay. (E) Transwell invasion assay images and (F) number of invading cells in the three groups. (G) Scratch migration assay images and $(\mathrm{H})$ would closure rate in the three groups. Cells were counted using a light microscope (magnification, $\mathrm{x} 100)$. $\mathrm{P}<0.05$ and ${ }^{* *} \mathrm{P}<0.01$, as indicated. HPA, heparanase; H. pylori or Hp, Helicobacter pylori.

When the MAPK inhibitor SB203580 was added to $H$. pylori-infected gastric cancer cells, the $H$. pylori-enhanced expression of HPA was decreased, as determined by RT-qPCR and western blotting. In addition, cell proliferation, invasion and migration were all decreased in $H$. pylori-infected MKN-45 cells treated with SB203580, as determined by the 

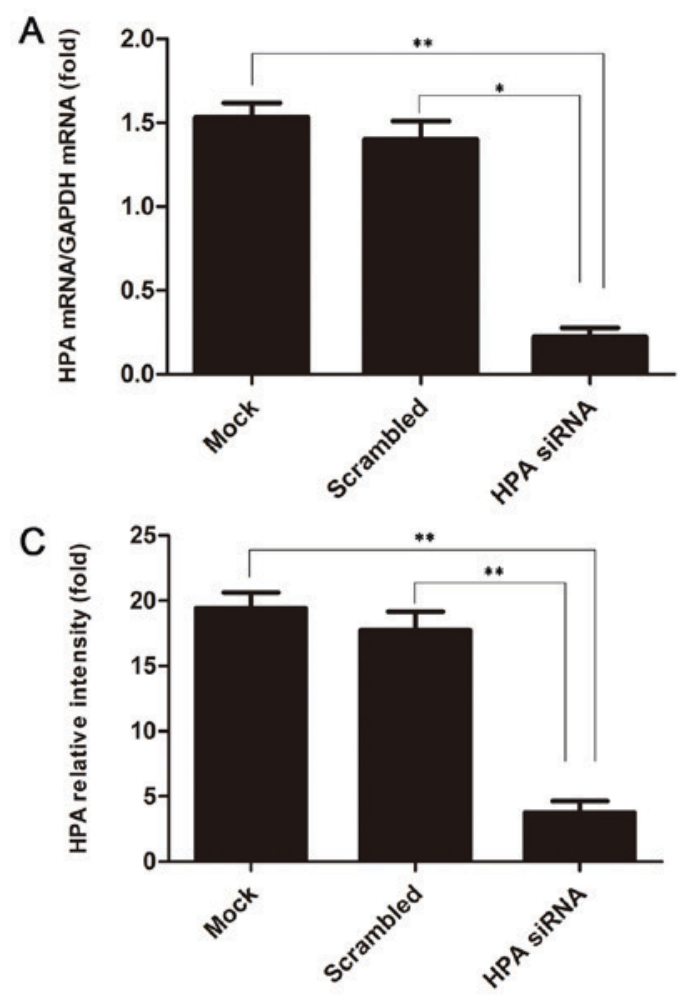

B
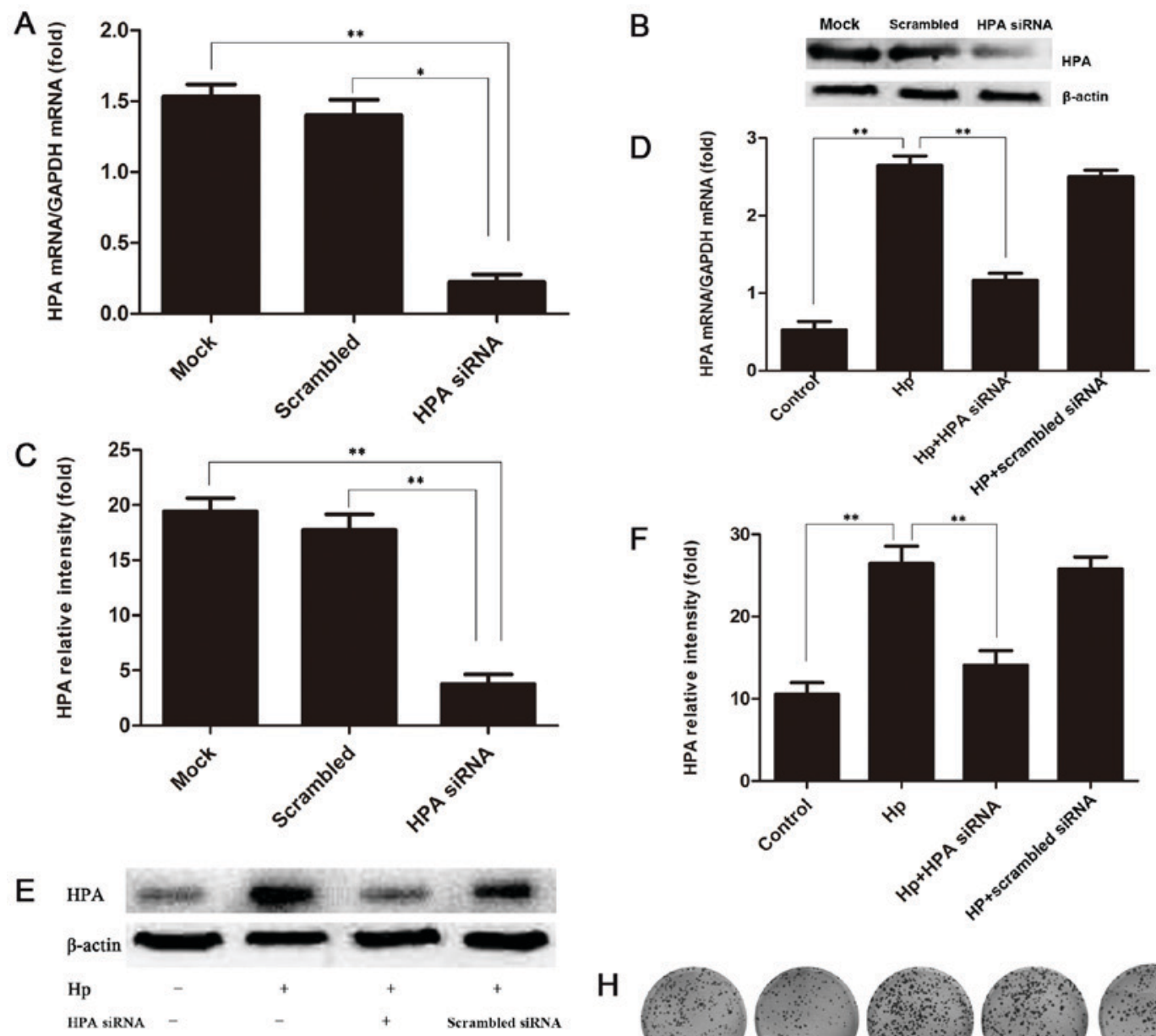

$\mathrm{H}$
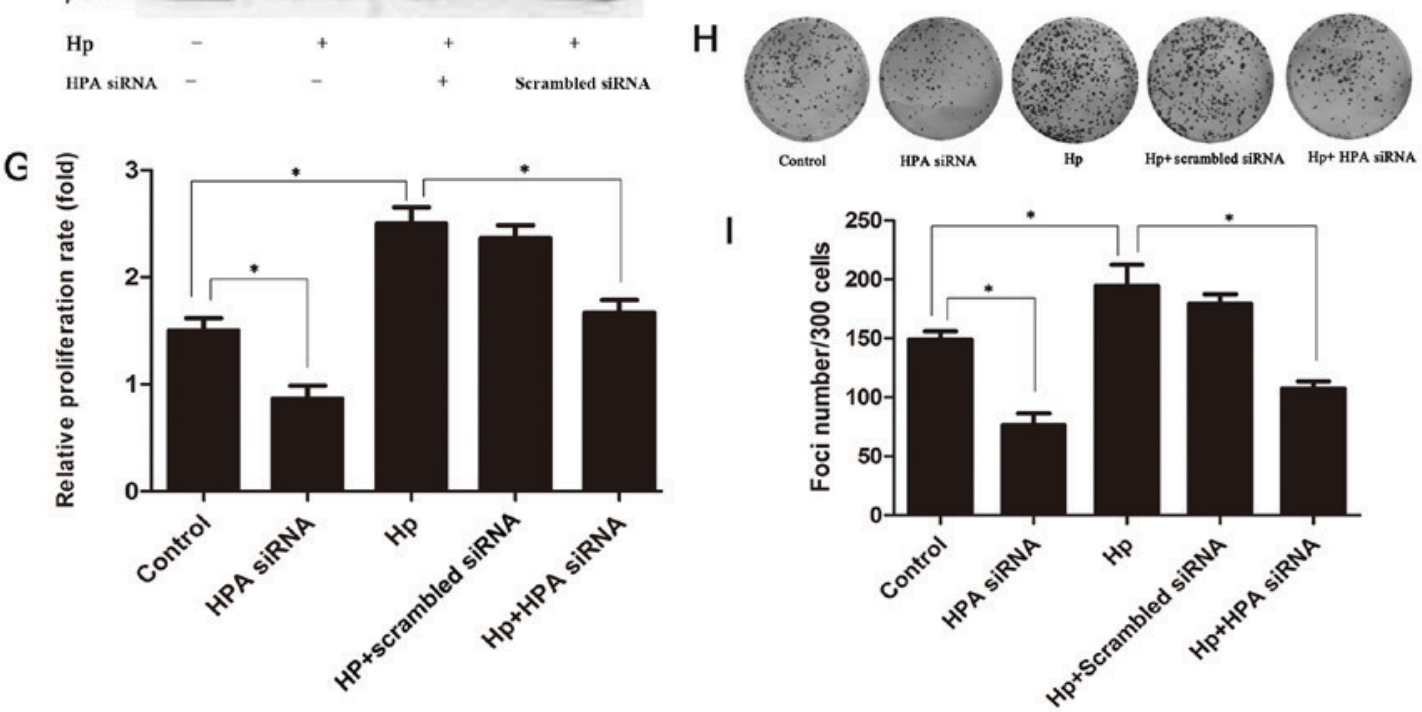

Figure 4. HPA inhibition attenuated the $H$. pylori-induced proliferation of MKN-45 cells. (A) Expression of HPA mRNA in MKN-45 cells transfected with siRNA against HPA. (B) Western blots and (C) quantified expression of the HPA protein in MKN-45 cells transfected with siRNA against HPA. (D) HPA mRNA expression, (E) western blots and (F) quantified HPA protein expression in H. pylori-infected HPA-knockout MKN-45 cells. (G) Cell proliferation determined using a Cell Counting kit-8 proliferation assay in H. pylori-infected HPA-knockout MKN-45 cells. (H) Images and (I) quantified results of colony formation assay in $H$. pylori-infected HPA-knockout MKN-45 cells. Cells were counted using a light microscope (magnification, $\mathrm{x} 100)$. ${ }^{*} \mathrm{P}<0.05$ and ${ }^{* *} \mathrm{P}<0.01$, as indicated. HPA, heparanase; H. pylori or Hp, Helicobacter pylori; siRNA, small interfering RNA.

CCK-8, Transwell and scratch assays, respectively. The results of these assays illustrated that $H$. pylori infection promoted HPA expression in gastric cancer cells via the MAPK signalling pathway, thus leading to enhanced cell proliferation, invasion and migration, which was then suppressed by the MAPK inhibitor.

Previous studies revealed that $H$. pylori infection and HPA cause cell proliferation (43-47). In the present study, the silencing of HPA significantly lowered the mRNA and protein expression levels of HPA in H. pylori-infected MKN-45 cells, and attenuated the proliferation and colony formation of these cells. These results implied that $H$. pylori infection induced the proliferation of gastric cancer cells through the upregulation of HPA. This mechanism illustrates that HPA may be a suitable therapeutic target for gastric cancer, particularly when induced by $H$. pylori infection. 
In conclusion, the results of the current study demonstrated that HPA serves a critical role in the development of gastric cancer in $H$. pylori-infected cells. This may be an important mechanism in the induction of gastric cancer by $H$. pylori infection. In addition, $H$. pylori infection may promote the proliferation, invasion and migration of gastric cancer cells through the upregulation of HPA expression, and this is may be mediated via the MAPK/NF- $\mathrm{kB}$ signalling pathway. Silencing HPA with siRNA transfection further confirmed that HPA was involved in the $H$. pylori-induced proliferation of MKN-45 cells. These data suggest that HPA may be used as a therapeutic target in the treatment of gastric cancer, particularly cancer induced by $H$. pylori infection. Additional investigation, including animal studies, is required to confirm the findings of the present study.

\section{Acknowledgements}

The authors of the present study would like to thank Dr Zhongtian Bai (The First Hospital of Lanzhou University, Gansu, China) for a critical reading of this manuscript. The authors appreciate the technical assistance provided by Professor Wenting He (The Second Hospital of Lanzhou University, Gansu, China).

\section{Funding}

The present study was supported by the Natural Science Foundation of Gansu Province (grant nos. 1506RJZA255 and 1308RJZA240-01), the Natural Science Foundation of China (grant no. 81572437), the International Science and Technology Cooperation Program of China (grant no. 2015DFA31650), the Open Topic of the Key Laboratory of Biological Treatment and Regenerative Medicine in Gansu Province (grant no. zdsyskfkt-201702) and the fund of Donggang Branch, The First Hospital of Lanzhou University (grant no. ldyydgyn-201705).

\section{Availability of data and materials}

The datasets used and/or analyzed during the current study are available from the corresponding author on reasonable request.

\section{Authors' contributions}

YL and LL designed the experiments. YZ and GF performed the experiments. LL produced the manuscript. BL and TS conducted data analysis.

\section{Ethics approval and consent to participate}

Not applicable.

\section{Patient consent for publication}

Not applicable.

\section{Competing interests}

The authors declare that they have no competing interests.

\section{References}

1. Ferlay J, Soerjomataram I, Ervik M, Dikshit R, Eser S, Mathers C, Rebelo M, Parkin DM, Forman D and Bray F: GLOBOCAN 2012 v1.0, Cancer incidence and mortality worldwide: IARC cancer base no. 11. International agency for research on cancer, 2013, Lyon, France. http://globocan.iarc.fr.

2. Ferlay J, Soerjomataram I, Dikshit R, Eser S, Mathers C, Rebelo M, Parkin DM, Forman D and Bray F: Cancer incidence and mortality worldwide: Sources, methods and major patterns in GLOBOCAN 2012. Int J Cancer 136: E359-E386, 2015.

3. Zhang XM, Wang Z, Liang JW and Zhou ZX: Analysis of laparoscopy-assisted gastric cancer operations performed by inexperienced junior surgeons. Asian Pac J Cancer Prev 15: 5077-5081, 2014.

4. Siegel RL, Miller KD and Jemal A: Cancer statistics, 2016. CA Cancer J Clin 66: 7-30, 2016.

5. Figueiredo C, Garcia-Gonzalez MA and Machado JC: Molecular pathogenesis of gastric cancer. Helicobacter 18 (Suppl 1): S28-S33, 2013.

6. Matsuda K, Tanikawa C and Nakamura Y: Possible role of genetic factors on reduced risk for gastric cancer among duodenal ulcer patients. Nihon Rinsho 71: 1491-1496, 2013.

7. Schistosomes, liver flukes and Helicobacter pylori. IARC Working Group on the evaluation of carcinogenic risks to humans. Lyon, 7-14 June 1994. IARC Monogr Eval Carcinog Risks Hum 61: 1-241, 1994.

8. Wang F, Meng W, Wang B and Qiao L: Helicobacter pylori-induced gastric inflammation and gastric cancer. Cancer Lett 345: 196-202, 2014.

9. Wang YH, Lv ZF, Zhong Y, Liu DS, Chen SP and Xie Y: The internalization of Helicobacter pylori plays a role in the failure of H. pylori eradication. Helicobacter 22, 2017.

10. Suerbaum S and Michetti P: Helicobacter pylori infection. N Engl J Med 347: 1175-1186, 2002.

11. Huang Y, Wang QL, Cheng DD, Xu WT and Lu NH: Adhesion and invasion of gastric mucosa epithelial cells by Helicobacter pylori. Front Cell Infect Microbiol 6: 159, 2016.

12. Li Z, Zou D, Ma X, Chen J, Shi X, Gong Y, Man X, Gao L, Zhao Y, Wang R, et al: Epidemiology of peptic ulcer disease: Endoscopic results of the systematic investigation of gastrointestinal disease in China. Am J Gastroenterol 105: 2570-2577, 2010.

13. Zhang M, Zhou YZ, Li XY, Tang Z, Zhu HM, Yang Y and Chhetri JK: Seroepidemiology of Helicobacter pylori infection in elderly people in the Beijing region, China. World J Gastroenterol 20: 3635-3639, 2014.

14. Vlodavsky I, Singh P, Boyango I, Gutter-Kapon L, Elkin M, Sanderson RD and Ilan N: Heparanase: From basic research to therapeutic applications in cancer and inflammation. Drug Resist Updat 29: 54-75, 2016.

15. Rivara S, Milazzo FM and Giannini G: Heparanase: A rainbow pharmacological target associated to multiple pathologies including rare diseases. Future Med Chem 8: 647-680, 2016.

16. Nadir Y and Brenner B: Heparanase multiple effects in cancer. Thromb Res 133 (Suppl 2): S90-S94, 2014.

17. Ilan N, Elkin M and Vlodavsky I: Regulation, function and clinical significance of heparanase in cancer metastasis and angiogenesis. Int J Biochem Cell Biol 38: 2018-2039, 2006.

18. Ni M, Elli S, Naggi A, Guerrini M, Torri G and Petitou M: Investigating glycol-split-heparin-derived inhibitors of heparanase: A study of synthetic trisaccharides. Molecules 21: E1602, 2016.

19. Vlodavsky I, Iozzo RV and Sanderson RD: Heparanase: Multiple functions in inflammation, diabetes and atherosclerosis. Matrix Biol 32: 220-222, 2013.

20. Wilson JC, Laloo AE, Singh S and Ferro V: 1H NMR spectroscopic studies establish that heparanase is a retaining glycosidase. Biochem Biophys Res Commun 443: 185-188, 2014.

21. Jin $\mathrm{H}$ and Zhou S: The functions of heparanase in human diseases. Mini Rev Med Chem 17: 541-548, 2017.

22. Yingying X, Yong Z, Zhenning W, Xue Z, Li J, Yang L and Huimian X: Role ofheparanase-1 in gastric carcinoma invasion. Asian Pac J Cancer Prev 10: 151-154, 2009.

23. Meirovitz A, Hermano E, Lerner I, Zcharia E, Pisano C, Peretz T and Elkin M: Role of heparanase in radiation-enhanced invasiveness of pancreatic carcinoma. Cancer Res 71: 2772-2780, 2011.

24. Shafat I, Pode D, Peretz T, Ilan N, Vlodavsky I and Nisman B: Clinical significance of urine heparanase in bladder cancer progression. Neoplasia 10: 125-130, 2008. 
25. Gingis-Velitski S, Zetser A, Kaplan V, Ben-Zaken O, Cohen E, Levy-Adam F, Bashenko Y, Flugelman MY, Vlodavsky I and Ilan N: Heparanase uptake is mediated by cell membrane heparan sulfate proteoglycans. J Biol Chem 279: 44084-44092, 2004.

26. Vreys V, Delande N, Zhang Z, Coomans C, Roebroek A, Dürr J and David G: Cellular uptake of mammalian heparanase precursor involves low density lipoprotein receptor-related proteins, mannose 6-phosphate receptors, and heparan sulfate proteoglycans. J Biol Chem 280: 33141-33148, 2005.

27. Ben-Zaken O, Shafat I, Gingis-Velitski S, Bangio H, Kelson IK, Alergand T, Amor Y, Maya RB, Vlodavsky I and Ilan N: Low and high affinity receptors mediate cellular uptake of heparanase. Int J Biochem Cell Biol 40: 530-542, 2008.

28. Hermano E, Lerner I and Elkin M: Heparanase enzyme in chronic inflammatory bowel disease and colon cancer. Cell Mol Life Sci 69: 2501-2513, 2012.

29. Schmidt EP, Yang Y, Janssen WJ, Gandjeva A, Perez MJ, Barthel L, Zemans RL, Bowman JC, Koyanagi DE, Yunt ZX, et al: The pulmonary endothelial glycocalyx regulates neutrophil adhesion and lung injury during experimental sepsis. Nat Med 18: 1217-1223, 2012.

30. Maeda S, Akanuma M, Mitsuno Y, Hirata Y, Ogura K, Yoshida H, Shiratori Y and Omata M: Distinct mechanism of Helicobacter pylori-mediated NF-kappa Bactivation between gastric cancer cells and monocytic cells. J Biol Chem 276: 44856-44864, 2001

31. Kim H, Lim JW and Kim KH: Helicobacter pylori-induced expression of interleukin- 8 and cyclooxygenase-2 in AGS gastric epithelial cells: Mediation by nuclear factor-kappaB. Scand J Gastroenterol 36: 706-716, 2001.

32. Zhang J, Chen Y, Xin XL, Li QN, Li M, Lin LP, Geng MY and Ding J: Oligomannurarate sulfate blocks tumor growth by inhibiting NF-kappaB activation. Acta Pharmacol Sin 31: 375-381, 2010

33. Wu WJ, Pan CE, Liu QG, Meng KW, Yu HB, Wang YL and Zhao L: Expression of heparanase and nuclear factor kappa B in pancreatic adenocarcinoma. Nan Fang Yi Ke Da Xue Xue Bao 27: 1267-1270, 2007 (In Chinese).

34. Wu W, Pan C, Yu H, Gong $\mathrm{H}$ and Wang Y: Heparanase expression in gallbladder carcinoma and its correlation to prognosis J Gastroenterol Hepatol 23: 491-497, 2008

35. Ding SZ, Smith MF Jr and Goldberg JB: Helicobacter pylori and mitogen-activated protein kinases regulate the cell cycle, proliferation and apoptosis in gastric epithelial cells. J Gastroenterol Hepatol 23: e67-e78, 2008.

36. Chen YC, Wang Y, Li JY, Xu WR and Zhang YL: $H$ pylori stimulates proliferation of gastric cancer cells through activating mitogen-activated protein kinase cascade. World J Gastroenterol 12: 5972-5977, 2006.

37. Xiang Y, Ye W, Huang C, Lou B, Zhang J, Yu D, Huang X, Chen B and Zhou M: Brusatol inhibits growth and induces apoptosis in pancreatic cancer cells via JNK/p38MAPK/NF-кb/Stat3/Bcl-2 signaling pathway. Biochem Biophys Res Commun 487: 820-826, 2017.

38. Chao W, Deng JS, Li PY, Liang YC and Huang GJ: 3,4-Dihydroxybenzalactone suppresses human non-small cell lung carcinoma cells metastasis via suppression of epithelial to mesenchymal transition, ROS-mediated PI3K/AKT/MAPK/MMP and NFKB signaling pathways. Molecules 22: E537, 2017.

39. Liu X, Fang H, Chen H, Jiang X, Fang D, Wang Y and Zhu D: An artificial miRNA against HPSE suppresses melanoma invasion properties, correlating with a down-regulation of chemokines and MAPK phosphorylation. PLoS One 7: e38659, 2012.

40. Livak KJ and Schmittgen TD: Analysis of relative gene expression data using real-time quantitative PCR and the 2(-Delta Delta C(T)) method. Methods 25: 402-408, 2001

41. Lin CJ, Liao WC, Lin HJ, Hsu YM, Lin CL, Chen YA, Feng CL, Chen CJ, Kao MC, Lai CH and Kao CH: Statins attenuate Helicobacter pylori CagA translocation and reduce incidence of gastric cancer: In vitro and population-based case-control studies. PLoS One 11: e0146432, 2016.

42. Choi IJ, Kim JS, Kim JM, Jung HC and Song IS: Effect of inhibition of extracellular signal-regulated kinase 1 and 2 pathway on apoptosis and bcl-2 expression in Helicobacter pylori-infected AGS cells. Infect Immun 71: 830-837, 2003.
43. Sachs G, Wen Y and Scott DR: Gastric infection by Helicobacter pylori. Curr Gastroenterol Rep 11: 455-461, 2009.

44. Ahn HJ and Lee DS: Helicobacter pylori in gastric carcinogenesis. World J Gastrointest Oncol 7: 455-465, 2015.

45. Goh LY,Leow AH and Goh KL: Observations on the epidemiology of gastrointestinal and liver cancers in the Asia-Pacific region. J Dig Dis 15: 463-468, 2014.

46. Wu BW, Li DF, Ke ZF, Ma D, Li YJ, Gang D, Zheng ZG, Zhang KJ and Zhang YH: Expression characteristics of heparanase in colon carcinoma and its close relationship with cyclooxygenase- 2 and angiogenesis. Hepatogastroenterology 57: 1510-1514, 2010.

47. Zhou Y, Song B, Qin WJ, Zhang G, Zhang R, Luan Q, Pan TJ, Yang AG and Wang H: Heparanase promotes bone destruction and invasiveness in prostate cancer. Cancer Lett 268: 252-259, 2008.

48. Varchalama E, Rodolakis A, Strati A, Papageorgiou T, Valavanis C, Vorgias G, Lianidou E and Antsaklis A: Quantitative analysis of heparanase gene expression innormal cervical, cervical intraepithelial neoplastic, and cervical carcinoma tissues. Int J Gynecol Cancer 19: 1614-1619, 2009.

49. Ma XM, Shen ZH, Liu ZY, Wang F, Hai L, Gao LT and Wang HS Heparanase promotes human gastric cancer cells migration and invasion by increasing $\mathrm{Src}$ and p38phosphorylation expression. Int J Clin Exp Pathol 7: 5609-5621, 2014.

50. Vlodavsky I, Ilan N, Naggi A and Casu B: Heparanase: Structure, biological functions, and inhibition by heparin-derived mimetics of heparan sulfate. Curr Pharm Des 13: 2057-2073, 2007.

51. Vlodavsky I, Friedmann Y, Elkin M, Aingorn H, Atzmon R, Ishai-Michaeli R, Bitan M, Pappo O, Peretz T, Michal I, et al: Mammalian heparanase: Gene cloning, expressionand function in tumor progression and metastasis. Nat Med 5: 793-802, 1999.

52. Mogler C, Herold-Mende C, Dyckhoff G, Jenetzky E, Beckhove P and Helmke BM: Heparanase expression in head and neck squamous cell carcinomas is associated with reduced proliferation and improved survival. Histopathology 58: 944-952, 2011.

53. Zheng L, Jiang G, Mei H, Pu J, Dong J, Hou X and Tong Q: Small RNA interference-mediated gene silencing of heparanase abolishes the invasion, metastasis and angiogenesis of gastric cancer cells. BMC Cancer 10: 33, 2010.

54. Tang W, Nakamura Y, Tsujimoto $M$, Sato $M$, Wang X, Kurozumi K, Nakahara M, Nakao K, Nakamura M, Mori I and Kakudo K: Heparanase: A key enzyme in invasion and metastasis of gastric carcinoma. Mod Pathol 15: 593-598, 2002.

55. Johnson GL and Lapadat R: Mitogen-activated protein kinase pathways mediated by ERK, JNK, and p38 protein kinases. Science 298: 1911-1912, 2002.

56. Chang L and Karin M: Mammalian MAP kinase signalling cascades. Nature 410: 37-40, 2001

57. Chen Y, Li H, Li M, Niu S, Wang J, Shao H, Li T and Wang H: Salvia miltiorrhizapolysaccharide activates $\mathrm{T}$ lymphocytes of cancer patients through activation of TLRs mediated-MAPK and -NF-кB signaling pathways. J Ethnopharmacol 200: 165-173, 2017.

58. Huang FT, Peng JF, Cheng WJ, Zhuang YY, Wang LY, Li CQ, Tang J, Chen WY, Li YH and Zhang SN: MiR-143 targeting TAK1 attenuates pancreatic ductal adenocarcinoma progression via MAPK and NF- $\kappa$ B pathway in vitro. Dig Dis Sci 62: 944-957, 2017.

59. Thakkar N, Yadavalli T, Jaishankar D and Shukla D: Emerging roles of heparanase in viral pathogenesis. Pathogens 6: E43, 2017

60. Ramani VC, Vlodavsky I, Ng M, Zhang Y, Barbieri P, Noseda A and Sanderson RD: Chemotherapy induces expression and release of heparanase leading to changes associated with an aggressive tumor phenotype. Matrix Biol 55: 22-34, 2016.

61. Hao NB, Tang B, Wang GZ, Xie R, Hu CJ, Wang SM, Wu YY, Liu E, Xie X and Yang SM: Hepatocyte growth factor (HGF) upregulates heparanase expression via PI3K/Akt/NF- $\kappa \mathrm{B}$ signaling pathway for gastric cancer metastasis. Cancer Lett 361: $57-66,2015$.

62. Cao HJ, Fang Y, Zhang X, Chen WJ, Zhou WP, Wang H, Wang LB and Wu JM: Tumor metastasis and the reciprocal regulation of heparanase gene expression by nuclear factor kappa $\mathrm{B}$ in human gastric carcinoma tissue. World J Gastroenterol 11: 903-907, 2005. 